\title{
André Blanc, Racine. Trois siècles de théâtre
}

\section{Benedetta Papasogli}

\section{(2) OpenEdition}

\section{Journals}

\section{Edizione digitale}

URL: https://journals.openedition.org/studifrancesi/40592

DOI: 10.4000/studifrancesi.40592

ISSN: 2421-5856

\section{Editore}

Rosenberg \& Sellier

\section{Edizione cartacea}

Data di pubblicazione: 1 juillet 2004

Paginazione: 180-181

ISSN: 0039-2944

\section{Notizia bibliografica digitale}

Benedetta Papasogli, «André Blanc, Racine. Trois siècles de théâtre», Studi Francesi [Online], 142 (XLVIII I I) | 2004, online dal 30 novembre 2015, consultato il 09 septembre 2021. URL: http://

journals.openedition.org/studifrancesi/40592 ; DOI: https://doi.org/10.4000/studifrancesi.40592

\section{Questo documento è stato generato automaticamente il 9 septembre 2021.}

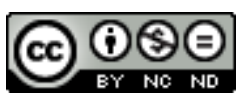

Studi Francesi è distribuita con Licenza Creative Commons Attribuzione - Non commerciale - Non opere derivate 4.0 Internazionale. 


\title{
André Blanc, Racine. Trois siècles de théâtre
}

\author{
Benedetta Papasogli
}

\section{NOTIZIA}

ANDRÉ BLANC, Racine. Trois siècles de théâtre, Paris, Fayard, 2003, pp. 733.

1 Sappiamo quanto sia stata ricca la raccolta del tricentenario raciniano, in edizioni e messe in scena, studi critici e opere di alta divulgazione. Ancora nella scia di quel fervore di studi sembra collocarsi l'opera di André Blanc, che sarebbe difficile definire una biografia data l'importanza che il sottotitolo - trois siècles de théâtre -, di primo acchito poco appariscente, assume in corso d'opera, sviluppando tutta un'ampia parte del volume dedicata alla vicenda postuma del poeta. Il libro si presenta dunque come una «summa» raciniana che non pretende di apportare luci nuove ma risistema con equilibrio molti materiali storico-critici, ed ha il merito di inglobare nella vasta rassegna finale anche i recenti dibattiti e contributi del tricentenario.

In realtà, se un critico letterario affronta uno studio biografico, sarà - ce ne accorgiamo ad apertura di libro - non tanto un approfondimento psicologico quanto la biografia di una creazione e di una fortuna letteraria. Dopo tutto, lo stesso André Blanc sottolinea che per quanto poco conosciamo l'uomo Racine - l'enigma Racine - pure ne sappiamo assai di più che non di altri grandi del suo tempo: ed è ben noto come il rapporto vitaopera, specie nella prima metà del XX secolo, sia stato il nodo di molti dibattiti raciniani. L'autore del ponderoso volume mantiene, non dico una neutralità, ma una esemplare sobrietà interpretativa, anche a rischio di una certa freddezza, di una presa di distanza che si riflette simmetricamente nel sentimento del lettore. Ancora una volta - ma potrebbe essere diversamente? - le isole fortunate, in questo periplo austero, sono le pagine dedicate alle tragedie, in cui la prospettiva storico-critica prevale con naturalezza sull'impostazione biografica. E non sorprenderà che le quasi cinquecento pagine della prima parte si concludano sull'interrogativo di sempre: «Qui était Racine?» 
3 Alcune messe a punto, alcuni accenti avviano ad intendere la risposta dello studioso. Notevole è il rilievo dato alla dimensione dell'amicizia, nel quadro tutto sommato sobrio della vita affettiva di Racine (ove stingono un poco anche le passioni giovanili legate all'esperienza dell'uomo di teatro). Ridimensonata la drammaticità del contrasto con Port-Royal; sfumata e bilanciata l'interpretazione del grande «silenzio» del poeta: André Blanc ha preparato il terreno per le sue conclusioni a favore di un Racine uomo di equilibrio, quasi armoniosamente passato attraverso fasi diverse di cui l'ultima non è quella del padre di famiglia assestato e del cortigiano fortunato, bensì il disgusto e il distacco e una sorta di ultima, insensibile «conversione».

4 Segue, come dicevamo, l'ampia carrellata su «tre secoli di teatro». E qui troviamo di tutto: sintesi sui vari periodi della critica intorno a Racine, ma anche notizie sulle messe in scena, documentazione e commento sui diversi «rôles» e sui maggiori attori che li hanno impersonati. Necessariamente veloce, questo Racine tel qu'en lui-même è tuttavia interessante e gustoso. Più che non la storia della critica è proprio la storia delle «créations» teatrali quella che si fa leggere volentieri. Certo, sono correttamente rivisitati i luoghi maggiori della critica raciniana, richiamati ad esempio, per il Novecento, i contributi di Pommier e di Picard, riassunta 1'impostazione di Goldmann, Mauron, Barthes, accennati i punti di vista diversi di Jean Rohou e di Georges Forestier... quello che manca è forse il senso dei rilievi, il fuoco di un dibattito. La scena si anima quando compaiono gli attori: da quelli contemporanei a Racine, a Adrienne Lecouvreur, a Talma e Rachel, ai «mostri sacri» dell'Otto e Novecento, evocati grazie alle più vive testimonianze coeve; e, ugualmente, quando avanzano i registi, fino alla ridda degli ultimi decenni, al genio, alla provocazione, al cattivo gusto, o alla perfezione filologica di messe in scena che ci sono vicinissime nel tempo. Manca alla rassegna la Fedra italiana del tricentenario: la intensa e discontinua Fedra di Mariangela Melato. Ma già siamo oltre la distanza di sicurezza della storiografia, e immersi nel vivacità precaria di una cronaca. 